\title{
Optimize the Transport Cost and Environmental Impact of Whey Collection: A Case Study in the Region Trentino A. A. (Italy)
}

\author{
Luca Iseppi, Franco Rosa*, Mario Taverna \\ University of Udine, Udine, Italy \\ Email: *rosa@uniud.it
}

How to cite this paper: Iseppi, L., Rosa, F. and Taverna, M. (2017) Optimize the Transport Cost and Environmental Impact of Whey Collection: A Case Study in the Region Trentino A. A. (Italy). American Journal of Operations Research, 7, 153-173. https://doi.org/10.4236/ajor.2017.73011

Received: December 12, 2016

Accepted: May 1, 2017

Published: May 4, 2017

Copyright $\odot 2017$ by authors and Scientific Research Publishing Inc. This work is licensed under the Creative Commons Attribution International License (CC BY 4.0). http://creativecommons.org/licenses/by/4.0/

\begin{abstract}
The scope of this research is to elaborate a strategy to minimize the logistic cost of the whey collection. The problem consists of the description of the whey collection basin and transport from CP (Cheese plant) to WPP (Whey processing plant). We started with an initial basic solution and proceeded with successive iterations to find the final optimal solution. Two numeric methods are proposed to solve iteratively the problem: the first one emulates the simplex method, the second one is an empirical solution to find the optimal route. Both are solved with an Excel and Google map software and do not require a dedicated LP program for calculus. The results demonstrate that both methods contribute to solve the transport problem and generate valuable information for the achievement of economic and environmental targets.
\end{abstract}

\section{Keywords}

Dairy Chain, Whey Production, Network Theory, Transportation Whey Optimization, Sustainability

\section{Introduction}

Milk and cheese production are important contributors of the Trentino A. A. (a mountain region in Nord-East Italy) economy. In 2015, 135.094 tons of milk were produced, mostly curled and strained for cheese production by a large number of small cheese plants scattered around the region, processing on average 14,000 liters of milk per day. The region is very sensitive to the circular economy paradigm and since a long time is trying to recycle the waste from agri-food activities. An important regional project is dedicated to recycle the whey, a polluting by-product of cheese production, representing the $85 \%-90 \%$ of the milk transformed in cheese. Using appropriate technologies is 
possible to separate the whey components and sell in different market channels: animal feedstock, proteins, vitamins for human consumption, lactose for PHA and others. Simulation about milk quota removal in Italy [1], estimate a loss of the producers' incomes about 4 billion $€$, caused by the fresh milk prices decrease between 5 and a $10 \%$ (under the baseline scenario) and a consumers' surplus gain of 3.7 billion $€$. [1] Figure 1 reports some historical changes in dairy sector in Italy: the number of dairy farms declined during the period 1995-2015 from 97,044 to 32,994 and the production increased from 10.4 million tons to 11.4 million tons. The $35 \%$ of largest dairy farms produce between 200 and more than 2000 tons per year, and cover the $88 \%$ of the total production [2]. Despite these events, the milk production still represents an interesting solution for many farmers; however consistent structural and organizational changes are required to increase the competitive advantage versus international competitors [3].

\section{Whey Production in Italy}

Milk, cheese and whey productions are strictly correlated: $10 \mathrm{~kg}$ of fresh milk produce approximately $1 \mathrm{~kg}$ of cheese and $9 \mathrm{~kg}$ of whey; the total cheese production in Italy it is estimated a quantity of whey between 8 and 9 million tons; lactose is the most important component (40-45 gr. per $\mathrm{Kg}$ of whey), and is responsible of the high values of BOD (Biochemical Oxygen Demand) (BOD: 40,000 - 60,000 ppm) and COD (Chemical Oxygen Demand) (COD: $50,000-80,000 \mathrm{ppm}$ ) if released into water bodies [4]. According to Wissmann et al. [5] the pollution caused by 50,000 liters (13,209 gallons) of whey is equivalent to a city settlement of 25,000 inhabitants. Nevertheless the whey can be a potential economic resource for the quantity of valuable components, at this moment only a small fraction of them are separated with ultrafiltration, fermentation, inverse osmosis methods and sold through different market channels [6]. The 53\% of the whey produced in Italy is dried, transformed in powder and exported in Germany and France excluding WPC-Whey Protein Concentrate and WPI-Whey Protein Isolate. In

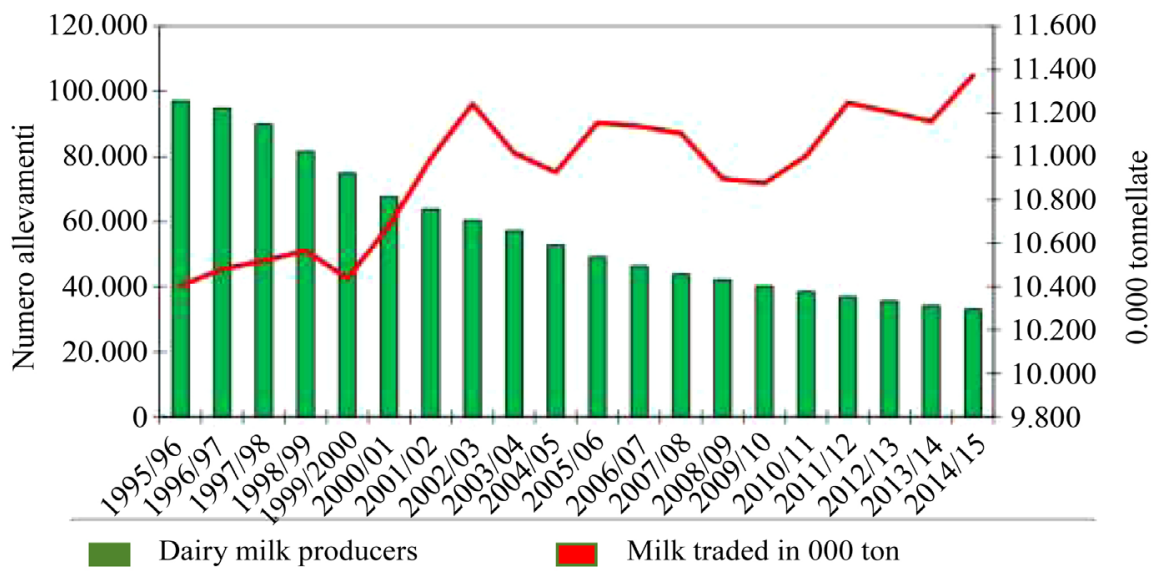

Figure 1. Trends of dairy plants (green line) and milk supply (red line) in Italy: period 1995-2014. 
Italy the largest whey quantity is used for animal feedstock (65\% of the total consumption), another $20 \%$ is sold as infant formulas and the remaining $15 \%$ is used in chocolate, ice cream, bakery and confectionery industry [9] [10].

In USA the whey powder used for animal feeding has a lower incidence (estimated 45\%); most of the whey is sold to the dairy industry. A growth of the whey consumption is expected in the nutritional segment; used in nutritional formulations such as whey powder, demineralized whey, WPC and WPI, whose demand in the health, pharmaceutic and nutritional sectors is expected to grow in next years, an interesting development is expected also in the Biopolymer industry. The derived whey products are growing at a rate of $3 \%$ per year, mostly for whey powder and lactose. With the progress in whey processing technologies, new market opportunities are disclosed to operators and the logistic of transport, packaging, storage, conservation and the environmental impact are becoming growingly important for the competitiveness of the dairy chain.

The purpose is to afford the transport problem due to shipping growing volumes of liquid whey at minimum transport cost from CP (cheese production) to WPP (whey processing) by selecting the optimal route to reduce cost and environmental impact. Preliminary information is requested about the dimension of the whey collection basin, transport costs, distance from (CP) to processing plant, (WPP), type of road (high way, state, trigonal or provincial and communal roads), road conditions, traffic intensity during the day, number of city crossed, physical obstacles orographic nature ${ }^{1}$. This information will be used to minimize both the transport costs, and the environmental impact caused by $\mathrm{CO}_{2}$ emissions [9] [10] [11] [12] [13].

This logistic problem requires to define:

1) The algebraic formulation of the objective function and constraints;

2) The balance condition that is the sum of the supplies of all the sources equal to the sum of the demands for all the destinations;

3) The selection of an iterative process to emulate the simplex algorithm, by starting with an initial basic feasible solution (IBFS), check for the demandsupply conditions and proceed iteratively to find the final optimal solution [10] [14] [15].

The remainder of this paper is structured as follows: Section 2 introduces the network theory, to find the optimum transport solution; Section 3 describes the whey supply in the basin with distances among CP and road network condition; Section 4 describes the case study based on the optimization approach; Section 5 reports the comments about results of simulation, policy implications and suggestions to improve the whey collection.

The contribution of the present paper to the transport problem is twofold. The first one is to introduce a novel formulation that extends a globally inclusive facility hierarchy problem [16] applied to whey collection and processing. The second is the contribution to the circular economy by reducing the impact caused by whey dispersion, and $\mathrm{CO}_{2}$ emission caused by 
transport distance ${ }^{2}$.

\section{The Network Theory}

The network theory requires some definitions: A graph is a set of junction points called nodes; each pair of contiguous nodes is connected with a line called branch (synonymous: "arcs," "links," or "edges"). The network is a set of connected nodes with flow of some type, the route is a sequence of branches connecting pair of nodes $i$ and $j$ in succession. This sequence of connected branches can be oriented from origin to a destination. The usual problem of the transport network is to minimize the route length from the origin node (start) to the destination node (end) by taking account of peculiar features of the road network. The graph is connected if there is a chain connecting every pair of nodes forming the route. If the route direction is also specified, the path is oriented. A cycle is a route connecting a node to itself. The optimization problem consists in selecting a set of connections forming a route between any two points of the network to minimize the cost of these connections [17] [18]

Definition: $k$ is the homogeneous commodity produced by a given $\mathrm{CP}$ and delivered through a route to the WPP that can be located in one of the CP of the network, assuming that any $\mathrm{CP}$ can be also a potential location of the WPP. The solution consists in finding the optimal route to minimize the transport costs and environmental impact caused by $\mathrm{CO}_{2}$ emissions [8]. The environmental impact is measured by assuming that the emission is a fixed quantity per $\mathrm{km}$, then the total emission is correlated to the route distance.

The following data are required to define this problem:

$k_{i}$ quantity of whey produced by a given $\mathrm{CP}$ and delivered to the next $\mathrm{CP}$ to the end WPP, $x_{i, p}$ variable that indicate if the link between nodes $i$ and $j$ is open; $c_{i j}$ is the unit cost of shipping the whey along the a given branch of the network.

Figure 2 describes the whey route from node $i$ (departure) to node $j$ (destination); with the assumption that CP $=\mathrm{WPP}, \quad i=1, \cdots, n$ and $j=1, \cdots, n$.

\section{Description of the Transport Problem for a Single Commodity}

The logistic of transport is an allocation problem illustrated in Figure 2: $m$ sources (CP) and $n$ destinations (WPP) in this case $n=m$ because every destination can



Figure 2. Scheme of a shipping circuit from node $i=1$ to three destination node $j=1, \cdots, 3$ along a circuit or with direct route.

${ }^{2}$ The WPP will use different technologies as concentration, demineralization, ultrafiltration, crystallization, PHA to separate the whey ingredients. 
be located in one of the sources; the whey route from node i (departure) to node $\mathrm{j}$ (destination). The $\mathrm{m}$ sources can ship the product to any of the $\mathrm{n}$ destinations at per unit carrying cost $c_{i j}$ (unit transportation cost from source $i$ to destination $j$ ). The transport problem requires to minimize the shipping cost of the whey commodity from a source CP defined the supply node $i$ to a destination node $j$ for $j=1 . . n$ defined the demand node. Along the transitory nodes it is completed the route from source $i$ to destination node $j$. As the CP (cheese plant) are interchangeable with WPP (whey processing plant), the possible WPP locations are equal to $\mathrm{CP}$ plants [17] so that the number of sources corresponds to the number of destination. The cost depends on the number of truckloads $\left(x_{i j}\right)$ shipping a given quantity of whey from source $i$ to destination $j$ and $c_{i j}$ is the cost per unit of commodity shipped from supply $i$ to destination $j$; this means that the transport cost depends on the distance. The accumulation of whey delivered by the all $C P_{i}$ represents the total supply then $s_{i}=\sum_{i=1}^{m} C P_{i}$ and the cumulated demand $d_{i}$ of the whey from all different $C P_{j}$ is $d_{j}=\sum_{j=1}^{n} C P_{j}$. In Figure 3 is reported an example the oriented graph network; node 1 is the origin (departure) and node 5 is the destination; two different routes are hypothesized in the example reported in Figure 3.

The $O . F$ is targeted to find the minimum transport cost of the product that passes through the branches from the initial node $i$ to the final node $j$ in a route constrained by the quantity of product shipped from origin to the destination. The Figure 3 describes the network formed by 5 nodes and 8 branches: node 1 , the origin is connected to the other nodes with 3 branches, node 2 has 4 optional branches, node 3 has 3 alternative branches, node 4 has 4 possible branches, node 5 the destination has 2 branches. The node 1 is the origin and node 5 is the destination; the example allows two routes: the route $\mathrm{A}$ is crossing the nodes 1, 2, 5 and gives the solution 1 ; the route $B$ is crossing the nodes $1,3,4$, 5 and gives the Solution 2 . The branches in red represent the route pattern, the branches in bleu are alternative choices and proceed toward the final node or

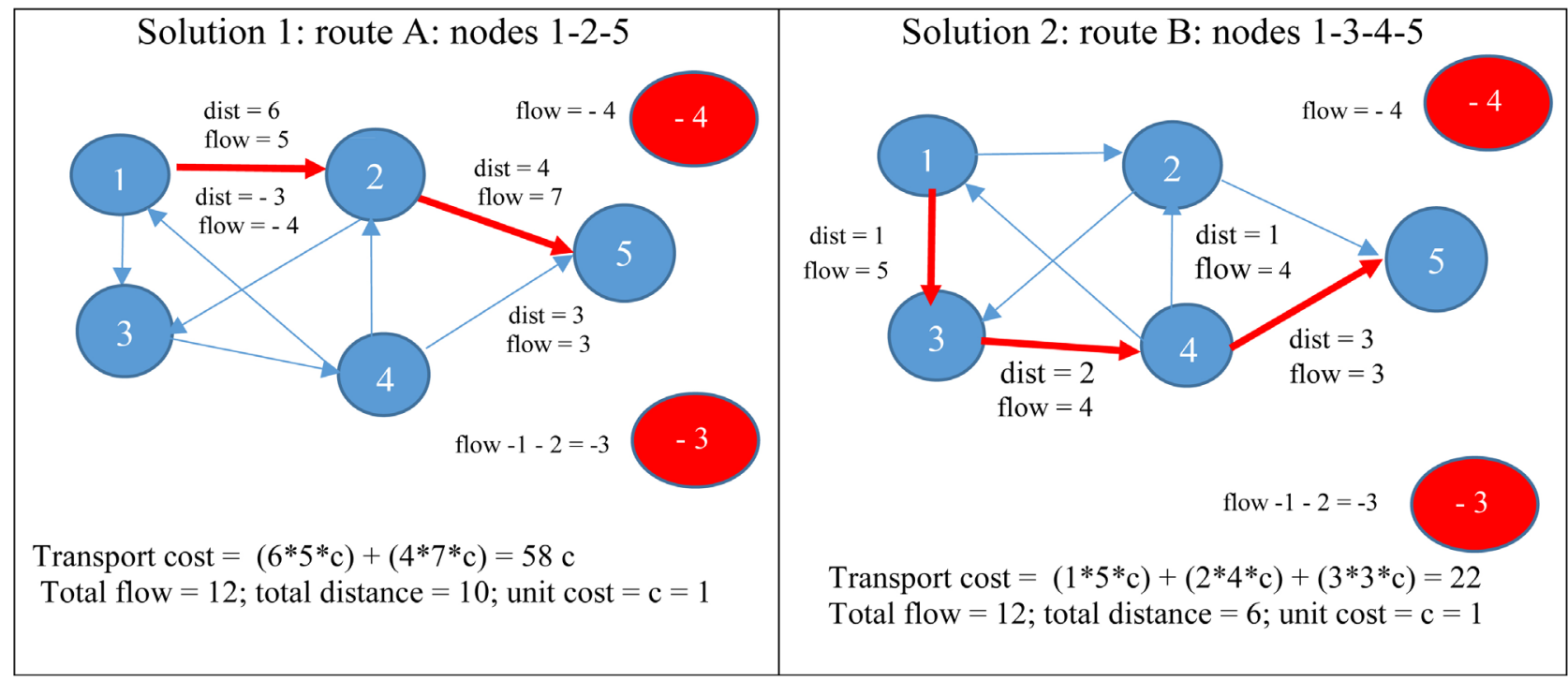

Figure 3. Example of the oriented graph composed by 5 nodes, 8 branches and two route solution. 
in opposite directions meaning that the flow direction is inverted .

With the route $A$, the branch connecting nodes 1 and 2 measures 6 and the flow is equal 5; the branch connecting nodes 2 and 5 measures 4 and the flow is 7. The final solution is given by a total flow equal to 12 , the total distance is 10 and the total transport cost, assuming the unit transport cost $c=1$ the total cost is 58 that is the value of the route $A$.

With route $B$ the length of the branch $1-3$ is 1 and allows a flow equal 5, the branch 3 - 4 measures 2 and allows a flow equal 4; the branch 4 - 5 measures 3 and allows a flow equal 3. The total flow is 12 equal to the solution 1 but the total distance is 22 and assuming a cost $c=1$, the solution is a transport cost $=22$ inferior to solution 1. Other routes can be hypothesized as the 1-3-4-2-5 or 1-3-4-1-2-5 but they are less efficient in normal route conditions to Solution 2.

\section{The Case Study}

The first step is to draw the graph of the road network for the collection basin reported in Figure 4, the $16 \mathrm{CP}$ (cheese plants) are the 16 nodes of our network in the Trentino A. A., a northern region of Italy, delivering the whey every day. The optimal position of the WPP will minimizes both the transport costs and

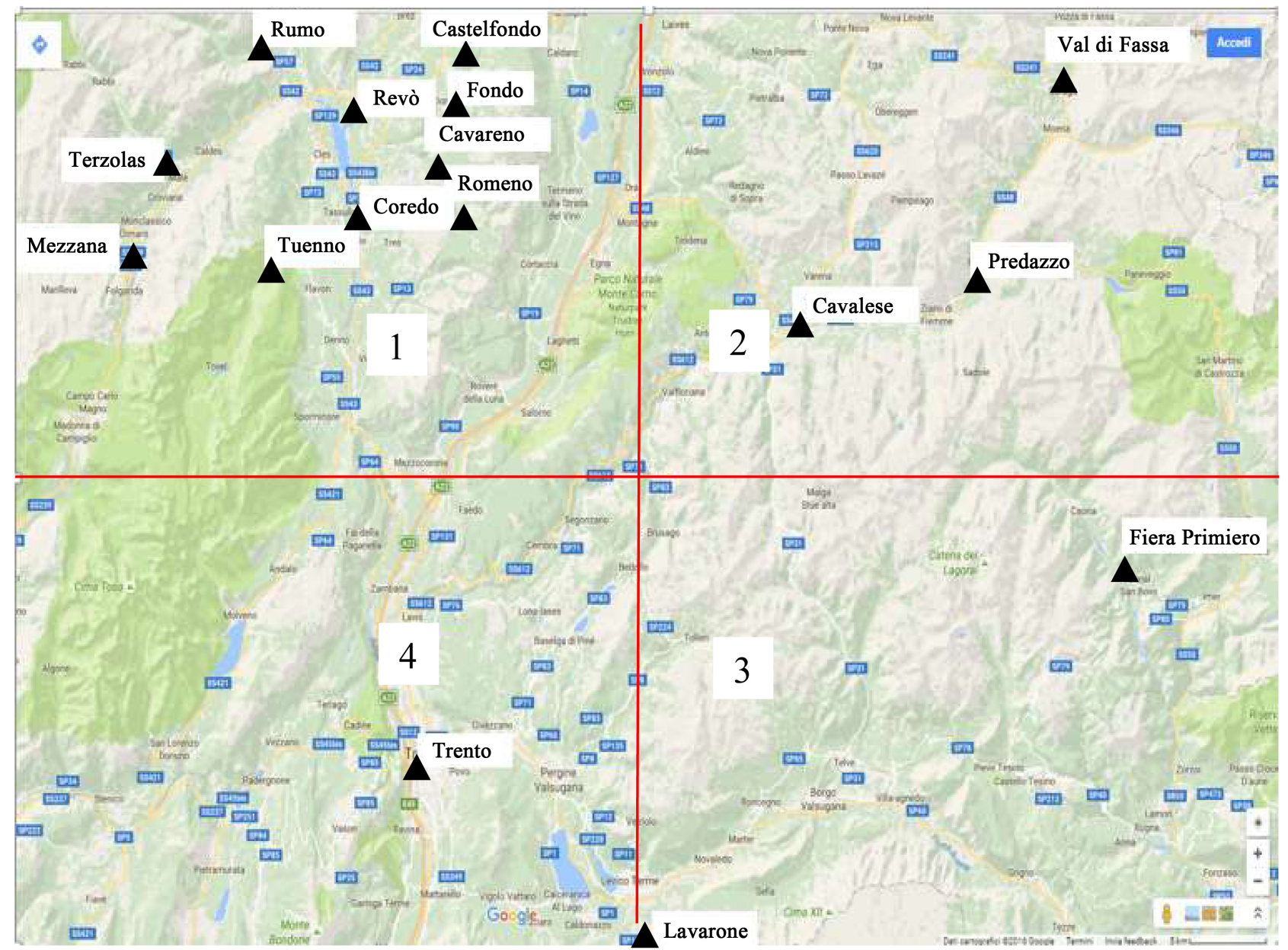

Figure 4. Distribution of the CP in the whey collection basin and the road mapof region Trentino A. A. 
environmental impact from CP to the WPP. Due to the orographic nature of this region, the road network is developed along vertical lines following the mountain compluvium lines: one is a highway and four state or province roads. The horizontal road development is represented by three state and province roads. This network configuration allows different route choices then the problem is to find the optimal route that will optimize the transport cost and environmental impact. The network indicates the concentration of ten CP in a restricted area of $45 \times 31$ square $\mathrm{km}$ that deliver the $55 \%$ of the total daily whey production; other six plants are distributed in an area of $93 \times 61$ square $\mathrm{km}$., that is four times larger compared to the first one and offers only the $45 \%$ of the total daily whey supply. This non homogeneous distribution of the $\mathrm{CP}$ affects the transport costs and will be taken into account to select the optimal transport solution.

The map reported in Figure 4 indicates the $\mathrm{CP}$ distribution in the collection basin. The graph is oriented to Trento where is located the processing plant, then a hypothesis of solution is to find the optimal route connecting all CP to the WPP located in Trento. Other WPP locations will be simulated for the cost minimization due to the different $\mathrm{CP}$ concentration. Observing the $\mathrm{CP}$ distribution and the road map it is possible to select three alternative routes to optimize the transport costs; these are indicated in Figure 5. The first route is a circuit connecting ten CP concentrated in the $1^{\text {st }}$ quadrant (see Figure 4) starting with Mezzana, the whey is shipped to the final destination Trento. A second route is a circuit that includes the CP located in Val di Fassa, Predazzo and Cavalese (2nd quadrant of Figure 4) and final whey delivery to Trento; the third route is a circuit including CP located in Fiera Primiero and Lavarone (3rd quadrant) and delivery to Trento.

In Table 1 is reported the daily quantity (hundred Kilos) of whey collected from the $16 \mathrm{CP}$ and collection cost from CP to WPP.

\section{Definition of the Network Problem}

From the literature two empirical procedures are selected to solve the transport

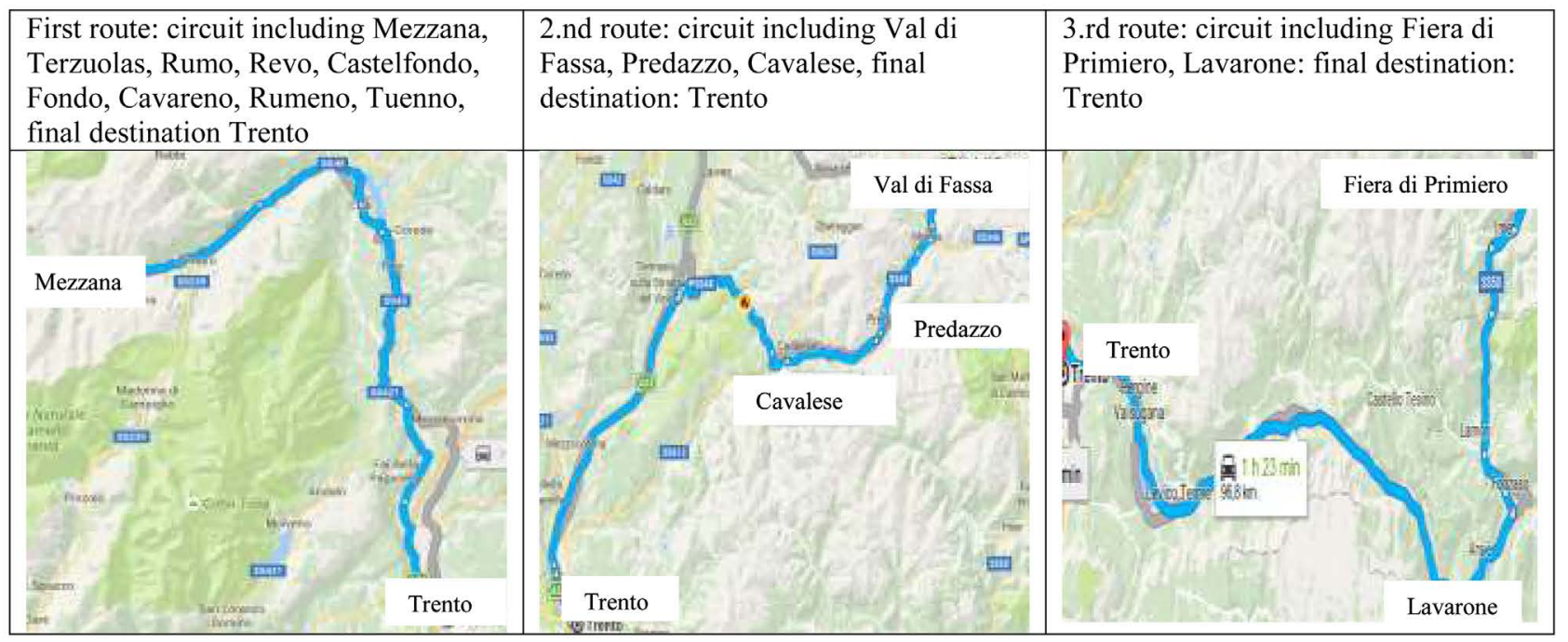

Figure 5. Three alternative routes for whey delivery to Trento. 
Table 1. Daily whey collected at the CP and cost $c_{i j^{\circ}}$

\begin{tabular}{ccc}
\hline Supply & daily delivery & cost \\
\hline Castelfondo & 137.25 & 91.96 \\
Cavalese & 172.30 & 115.44 \\
Cavareno & 87.79 & 58.82 \\
Coredo & 92.96 & 62.28 \\
Fondo & 82.47 & 55.25 \\
Latte Trento & 347.44 & 232.78 \\
Lavarone & 33.60 & 22.51 \\
Mezzana & 106.75 & 71.52 \\
Predazzo & 106.48 & 71.34 \\
Primiero & 114.36 & 76.62 \\
Revò & 26.16 & 17.52 \\
Romeno & 175.92 & 117.87 \\
Rumo & 102.27 & 68.52 \\
Terzolas & 146.64 & 98.25 \\
Tuenno & 65.12 & 43.63 \\
Val di Fassa & 58.71 & 39.34 \\
Sabbionara & 0.00 & 0.00 \\
TN Consorzio & 0.00 & 0.00 \\
Total & 1856.20 & 1243.66 \\
\hline
\end{tabular}

problem: The first one is a numerical solution that emulate the simplex method and proceeds with successive iterations starting with an initial minimum cost value, proceeding to the next minimum cost and finally it is obtained the final minimum cost value. At the beginning the minimum cost cell is selected the corresponding row (supply) and column (demand) is selected at the crossing of row (supply) and column (demand) and the residual is calculated by finding the positive difference between demand and supply (or vice versa) and proceeds by finding the next minimum cost. [12] [13].

The second procedure is more empirically oriented, and uses the observation of the network to choose the preferred route.

The advantage is that if the network features and road conditions are known it is simpler to solve the problem and allow to perform easily many simulations. Alternatively one can use some algorithm (i.e. the Dijkstra algorithm) to find the shortest route.

The network is composed by $i=1, \cdots, m$ sources (CP suppliers) and $j=1, \cdots, n$ destinations (customers): each sources $C P_{i}$ supplies $x_{i j}$ quantity of whey to the next $j$ destinations at per unit shipping cost $C_{i j}$ that is the transport cost per unit of whey shipped from source $i$ to destination $j$. Each source $i$ for $1 \leq i \leq m$ delivers $s i$ quantity to $n$ destinations (customers) and the destination demands $d_{j}$ for $1 \leq j \leq n$. The supply constraints $i$ is the flow limit of whey from the origin supply node $i$ to the $n$ destination (consumption) nodes $j$; the demand constraints (see column) indicate the quantity of product from the all origin nodes $i$ allocated to one destination node $j$. 
The total supply is the sum of the product delivered by a given $\mathrm{CP}$ to destination, then:

$s_{i}=\sum_{i=1}^{m} s_{i j}$; the demand is the sum of $d_{i j}$ units, offered by the all $C P_{p}$ then $d_{i}=\sum_{i=1}^{n} d_{i j}$ this is the demand at every location. If origins and destinations coincide the problem can be represented by a square table with source $i$ equal to destination $j$ so that $\mathrm{m}$ rows equal to $n$ columns.

The transport problem consists in the formulation of the objective function $Z$ that is the transport cost minimization bounded with the supply and demand constraints as indicated below:

$\operatorname{Min} Z=\sum_{i=1}^{m} \sum_{j=1}^{n} c_{i j} * X_{i j} \quad$ (for all branches)

subject to

$\sum_{j=1}^{n} x_{i j} \leq s_{i}$ for $i=1,2, \cdots, m$ (supply constraint; row $m$ )

$\sum_{i=1}^{m} x_{i j} \leq d_{j}$ for $j=1,2, \cdots, n$ for $j=1,2, \cdots, n$ (demand constraint; column $n$ )

$\sum_{i=1}^{m} s_{i}=\sum_{j=1}^{n} d_{j} \quad$ (equality constraint for balance problem)

$X_{i i} \geq 0$ for all $i, j$ (positive or non negatives)

The OF with supply and demand constraints are reported in extended notation below:

$$
\begin{aligned}
\operatorname{Min} Z= & c_{11} x_{11}+c_{12} x_{12}+\cdots+c_{1 n} x_{1 n}+c_{21} x_{21}+c_{22} x_{2,2}+\cdots+c_{2 n} x_{2 n} \\
& +\cdots+c_{m 1} x_{m 1}+c_{m 2} x_{m 2}+\cdots+c_{m n} x_{m n}
\end{aligned}
$$

subject to:

1) Supply constraints (row $1 \ldots 16$ )

$$
\begin{gathered}
x_{11}+x_{12}+\cdots+x_{1 n} \leq s_{1} \\
x_{21}+x_{22}+\cdots+x_{2 n} \leq s_{2} \\
x_{m 1}+x_{m 2}+\cdots+x_{m n} \leq s_{m}
\end{gathered}
$$

2) Demand constraints (column 1...16)

$$
\begin{aligned}
& x_{11}+x_{21}+\cdots+x_{m 1} \leq d_{1} \\
& x_{12}+x_{22}+\cdots+x_{m 2} \leq d_{2} \\
& x_{1 n}+x_{2 n}+\cdots+x_{m n} \leq d_{n}
\end{aligned}
$$

The Table 2 reports the information required to solve the problem:

1) For each branch $i$-, $j$ is reported: The distance $d_{i j}$ in $\mathrm{km}$ from node $i$ to node $j$, adjusted with time varying with local network conditions affecting the transport difficulty. The adjusted distance in $\mathrm{km} X_{i j}$ is included in the OF.

2) $c_{i j}$ is the cost of shipping one unit of whey from $i$ to $j$ then $c_{i j}=0.67 * d_{i j}$ expressed in $€ / 100 \mathrm{Kg}$.

The data of Table 2 are used to elaborate the transport problem reported here:

$$
\begin{aligned}
\text { F.O } & 10.05 x_{12}+26.13 x_{13}+22.78 x_{14}+30.82 x_{15} \\
& +32.83 x_{16}+33.5 x_{17}+30.15 x_{18}+26.80 x_{19} \\
& +22.78 x_{1,10}+43.55 x_{1,11}+64.32 x_{1,12}+75.04 x_{1,13} \\
& +88.44 x_{1,14}+93.8 x_{11,5}+76.38 x_{11,6}+10.05 x_{2,1} \\
& +18.76 x_{2,3}+18.09 x_{2,4}+\cdots+68.34 x_{16,15}
\end{aligned}
$$


Table 2. Network table with unit cost and distances. In red is reported the minimum costs for a given column.

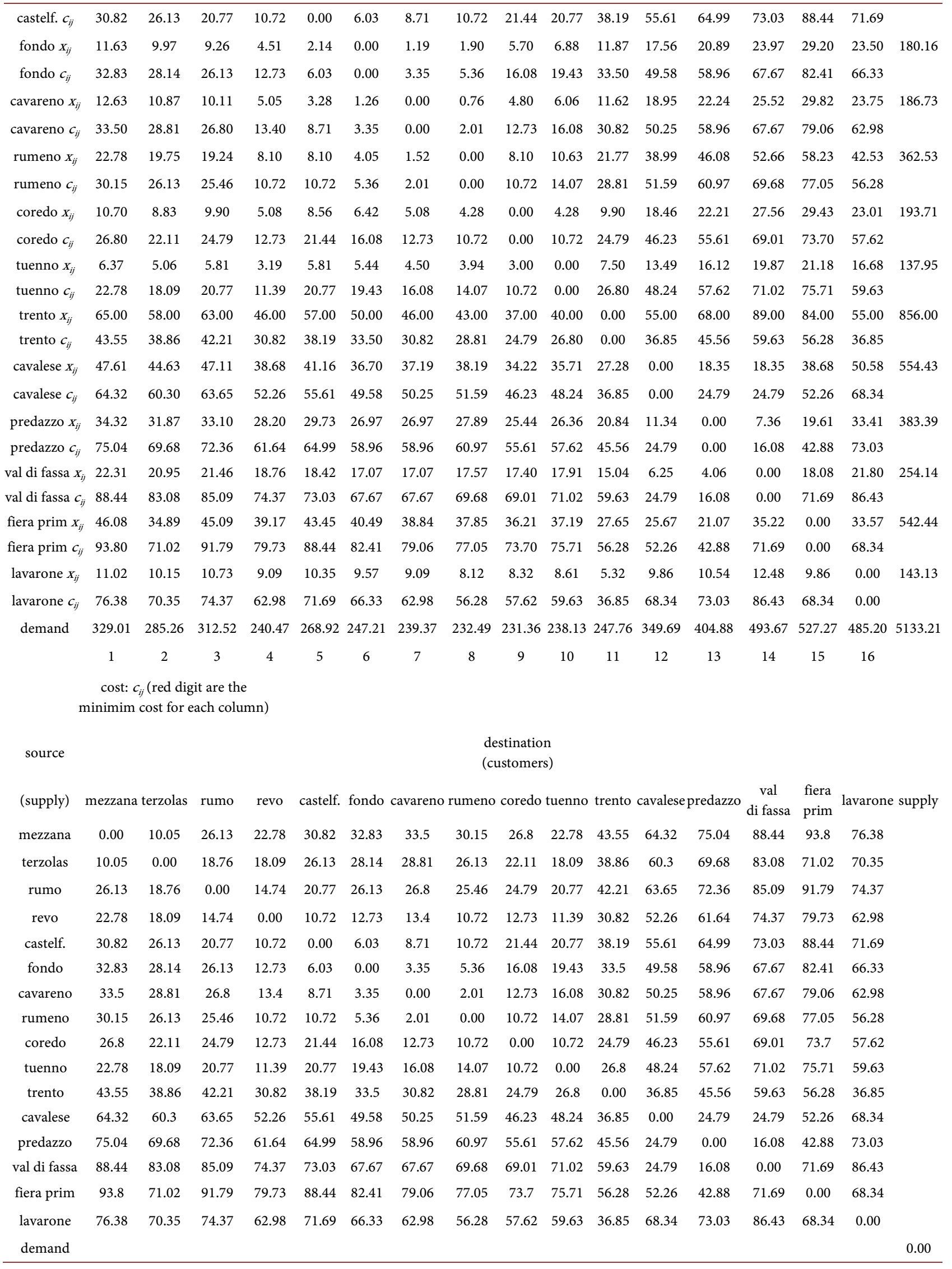


S. to

supply constraint $(n r=16)$

$$
\begin{gathered}
x_{1,2} X_{1,2}+X_{1,3}+X_{1,4}+X_{1,5}+X_{1,6}+X_{1,7}+X_{1,8}+X_{1,9}+X_{1,10} \\
+X_{1,11}+X_{1,12}+X_{1,13}+X_{1,14}+X_{1,15}+X_{1,16} \leq 310.63 \\
x_{16,1}+X_{16,2}+X_{16,3}+X_{16,4}+X_{16,5}+X_{16,6}+\cdots+X_{16,55} \leq 143.13
\end{gathered}
$$

demand constraint $(n r=16)$

$$
\begin{aligned}
& x_{1,1}+X_{2,1}+X_{3,1}+X_{4,1}+X_{5,1}+X_{6,1}+X_{7,1}+X_{8,1}+X_{9,1} \\
& +X_{10,1}+X_{11,1}+X_{12,1}+\cdots+X_{13,1}+X_{14,1}+\cdots+X_{16,1} \leq 329.01 \\
& x_{1,16}+X_{2,16}+X_{3,16}+X_{4,16}+X_{5,16}+\cdots X_{16,16}+\cdots+\leq 485.20
\end{aligned}
$$

Procedure $1-$ To find the optimal solution is required the following steps:

Step 1-Define the OF: the transport cost minimization by selecting a route composed by nodes (CP) and branches, supply (row) and demand (column) constraints;

Step 2-Check for the balance condition: sum of row values equal to sum of column values;

Step 3-Find the minimum transport cost value $c_{i j}$ in the transport Table 2 and select the corresponding cell;

Step 4-First allocation: find the smaller value by comparing $s_{i}$ and $d_{j}$ referred to cell $c_{i j}$ (in our case min $c_{i j}=2.01$ in cell 8,7 and the smaller value between $s_{i}=362.53$ and $d_{j}=239.37$ is $s_{i}$. Allocate $X_{i j}=$ supply value (in this case is 23,937 in the corresponding cell $(i, j)$ and compute the difference: 362.53 $239.37=123.16$ that is the residual supply value.

Step 5-Second allocation: search for the next minimum cost $C_{i j}$ corresponding to value 3.35 in cell 7, 6 and $s_{7}=185.73$ and $d_{6}=247.21$. The residual supply $s_{7}=123.16$ is is compared with $d_{6}$ that is greater so Residual $d_{j}=247.21-123.16=124.05$ and supply go to 0 ; this value is the new reduced demand allocated in the new cell $c_{i j}$. Proceeding with these operations, the supply and demand requirements are progressively allocated, allowing to compute the partial costs of allocation at each step.

The min $C_{i j}$ from the 16 columns reported in Table 2 are listed here:

$$
\begin{aligned}
& c_{8,7}=2.01 ; c_{7,6}=3.35 ; c_{6,8}=5.36 ; c_{6,5}=6.03 ; c_{2,1}=10,05 \\
& c_{10,9}=10.72 ; c_{4,10}=11.39 ; c_{4,3}=14.74 ; c_{10,2}=18.09 ; c_{9,11}=24.79 ; \\
& c_{13,12}=24.80 ; c_{11,16}=36.85 ; c_{13,15}=42.88
\end{aligned}
$$

The cost minimizations obtained with successive iterations are reported in Table 3; 15 iterations were required to find the optimal allocation for the most general network configuration that included all branches of the network

Simulation 2: For this simulation, the all CP of the first route are excluded from route 2 and 3 (value $=0$ ) a priori because inefficient in term of distance and time as suggested by the Google map and roads previously observed in Figure 4 and Figure 5 then the new Table 4 is used for finding the optimal solution.

In Table 5 are reported the intermediate transport values with elimination of some road alternatives. 
Table 3. Iterative process to find the optimal transport cost.

\begin{tabular}{|c|c|c|c|c|c|c|c|c|c|c|c|}
\hline & $\begin{array}{l}\text { Minimum } \\
\text { cost }\end{array}$ & Cell position & $\begin{array}{l}\text { Demand } \\
\text { (column) } d_{j}\end{array}$ & & $\begin{array}{l}\text { Supply } \\
\text { (row) } s_{i}\end{array}$ & & Minimum & Difference & & & Transport \\
\hline allocation & value & $\begin{array}{c}i=\text { row } \\
j=\text { column }\end{array}$ & position & value & position & value & $\left(d_{j} s_{i}\right)$ & value-min & $\operatorname{resid} d_{j}$ & resid $s_{i}$ & cost \\
\hline first allocation & 2.01 & $8-7$ & d7 & 239.37 & s8 & 362.53 & d7 & 123.16 & 0.00 & 123.16 & 247.55 \\
\hline 2.nd allocation & 3.35 & $7-6$ & d6 & 247.21 & res s8 & 123.16 & s8 & 123.16 & 124.05 & 0 & 415.57 \\
\hline 3.rd allocation & 5.36 & $6-8$ & resid d & 124.05 & s6 & 180.16 & resid d & 124.05 & 0.00 & 56.11 & 300.74 \\
\hline 4.th allocation & 6.03 & $6-5$ & d5 & 268.92 & resid s & 56.11 & resid d & 212.81 & 212.81 & 0 & 1283.26 \\
\hline 5.th allocation & 10.05 & $2-1$ & s2 & 371.41 & resid d & 212.81 & resid s & 158.60 & 0.00 & 158.60 & 1593.92 \\
\hline 6.th allocation & 10.72 & $10-9$ & resid s & 158.60 & resid d & 231.36 & resid s & 158.60 & 72.76 & 0 & 780.01 \\
\hline 7.th allocation & 11.39 & $4-10$ & resid d & 72.76 & s4 & 54.96 & resid d & 17.80 & 17.80 & 0 & 202.72 \\
\hline 8.th allocation & 12.73 & $6-4$ & resid d & 17.80 & s6 & 180.16 & resid d & 17.80 & 0.00 & 162.36 & 2066.87 \\
\hline 9.th allocation & 14.74 & $4-3$ & resid s & 162.36 & d3 & 312.52 & resid d & 150.15 & 150.15 & 0 & 2213.28 \\
\hline 10.th allocation & 16.08 & $13-14$ & resid d & 150.15 & s13 & 383.39 & resid d & 150.15 & 0.00 & 233.24 & 3750.50 \\
\hline 11.th allocation & 18.09 & $10-2$ & resid s & 233.24 & $\mathrm{~d} 2$ & 285.26 & resid s & 233.24 & 52.02 & 0 & 941.11 \\
\hline 12.th allocation & 24.79 & $9-11$ & resid d & 52.02 & s9 & 193.71 & resid d & 52.02 & 0.00 & 141.69 & 3512.43 \\
\hline 13.th allocation & 24.79 & $13-12$ & resid s & 141.69 & $\mathrm{~d} 12$ & 349.69 & resid s & 141.69 & 208.01 & 0 & 5156.49 \\
\hline 14.th allocation & 36.85 & $11-16$ & resid d & 208.01 & s11 & 856.00 & resid d & 208.01 & 0.00 & 647.99 & $23,878.55$ \\
\hline 15.th allocation & 37.65 & $12-15$ & resid s & 647.99 & d15 & 516.46 & resid d & 516.46 & 0.00 & 131.53 & 4952.10 \\
\hline
\end{tabular}

Table 4. Simulation 2-this table is adjusted from Table 2 with deletion of some destinations from the network.

\begin{tabular}{|c|c|c|c|c|c|c|c|c|c|c|c|c|c|c|c|c|c|}
\hline $\begin{array}{l}\text { source } \\
\text { (supply) }\end{array}$ & \multicolumn{17}{|c|}{$\begin{array}{l}\text { destination } \\
\text { (customers) }\end{array}$} \\
\hline mezzana & 0.00 & 4.61 & 11.98 & 10.45 & 14.13 & 15.06 & 15.36 & 13.83 & 12.29 & 10.45 & 19.97 & 0.00 & 0.00 & 0.00 & 0.00 & 0.00 & 128.12 \\
\hline terzolas & 6.33 & 0.00 & 11.82 & 11.40 & 16.46 & 17.73 & 18.15 & 16.46 & 13.93 & 11.40 & 24.48 & 0.00 & 0.00 & 0.00 & 0.00 & 0.00 & 148.14 \\
\hline rumo & 11.48 & 8.24 & 0.00 & 6.48 & 9.12 & 11.48 & 11.77 & 11.19 & 10.89 & 9.12 & 18.54 & 0.00 & 0.00 & 0.00 & 0.00 & 0.00 & 108.32 \\
\hline revo & 2.56 & 2.03 & 1.66 & 0.00 & 1.20 & 1.43 & 1.51 & 1.20 & 1.43 & 1.28 & 3.46 & 0.00 & 0.00 & 0.00 & 0.00 & 0.00 & 17.77 \\
\hline castelf. & 18.17 & 15.41 & 12.25 & 6.32 & 0.00 & 3.56 & 5.14 & 6.32 & 12.64 & 12.25 & 22.52 & 0.00 & 0.00 & 0.00 & 0.00 & 0.00 & 114.56 \\
\hline fondo & 11.63 & 9.97 & 9.26 & 4.51 & 2.14 & 0.00 & 1.19 & 1.90 & 5.70 & 6.88 & 11.87 & 0.00 & 0.00 & 0.00 & 0.00 & 0.00 & 65.04 \\
\hline cavareno & 12.63 & 10.87 & 10.11 & 5.05 & 3.28 & 1.26 & 0.00 & 0.76 & 4.80 & 6.06 & 11.62 & 0.00 & 0.00 & 0.00 & 0.00 & 0.00 & 66.45 \\
\hline coredo & 0.00 & 0.00 & 0.00 & 0.00 & 0.00 & 0.00 & 0.00 & 0.00 & 0.00 & 4.28 & 9.90 & 0.00 & 0.00 & 0.00 & 0.00 & 0.00 & 14.18 \\
\hline tuenno & 0.00 & 0.00 & 0.00 & 0.00 & 0.00 & 0.00 & 0.00 & 0.00 & 0.00 & 0.00 & 7.50 & 0.00 & 0.00 & 0.00 & 0.00 & 0.00 & 7.50 \\
\hline trento & 0.00 & 0.00 & 0.00 & 46.00 & 57.00 & 0.00 & 0.00 & 0.00 & 37.00 & 40.00 & 0.00 & 55.00 & 68.00 & 89.00 & 84.00 & 55.00 & 531.00 \\
\hline cavalese & 0.00 & 0.00 & 0.00 & 0.00 & 0.00 & 0.00 & 0.00 & 0.00 & 0.00 & 0.00 & 0.00 & 0.00 & 18.35 & 18.35 & 38.68 & 50.58 & 125.96 \\
\hline predazzo & 0.00 & 0.00 & 0.00 & 0.00 & 0.00 & 0.00 & 0.00 & 0.00 & 0.00 & 0.00 & 20.84 & 11.34 & 0.00 & 7.36 & 19.61 & 33.41 & 92.55 \\
\hline $\begin{array}{c}\text { val } \\
\text { di fassa }\end{array}$ & 0.00 & 0.00 & 0.00 & 0.00 & 0.00 & 0.00 & 0.00 & 0.00 & 17.40 & 17.91 & 15.04 & 6.25 & 4.06 & 0.00 & 18.08 & 21.80 & 100.54 \\
\hline fiera prim & 0.00 & 0.00 & 0.00 & 0.00 & 0.00 & 0.00 & 0.00 & 0.00 & 36.21 & 37.19 & 27.65 & 25.67 & 21.07 & 35.22 & 0.00 & 33.57 & 216.58 \\
\hline lavarone & 0.00 & 0.00 & 0.00 & 0.00 & 0.00 & 0.00 & 0.00 & 0.00 & 0.00 & 0.00 & 5.32 & 0.00 & 0.00 & 0.00 & 0.00 & 0.00 & 5.32 \\
\hline demand & 85.59 & 70.87 & 76.31 & 98.30 & 111.45 & 54.56 & 54.63 & 51.65 & 160.39 & 167.46 & 220.48 & 98.27 & 111.47 & 149.92 & 160.38 & 194.36 & 1866.09 \\
\hline
\end{tabular}


Table 5. The allocation steps required to find the optimal solution.

\begin{tabular}{|c|c|c|c|c|c|c|c|c|c|c|c|}
\hline & $\begin{array}{l}\text { Minimum } \\
\text { cost }\end{array}$ & cell position & $\begin{array}{l}\text { supply } \\
\text { (row) } s_{i}\end{array}$ & & $\begin{array}{c}\text { demand } \\
\text { (column) } d_{j}\end{array}$ & & Minimum & difference & & & transport \\
\hline allocation & value & $\begin{array}{c}i=\text { row; } \\
j=\text { column }\end{array}$ & position & value & position & value & $\left(d_{\rho}, s_{i}\right)$ & value-min & resid $d_{j}$ & resid $s_{i}$ & cost \\
\hline first allocation & 10.05 & $2-1$ & s2 & 371.41 & d1 & 379.39 & & & 7.98 & 0.00 & 80.18 \\
\hline 2.nd allocation & 18.09 & $10-2$ & s10 & 137.95 & $\mathrm{~d} 2$ & 335.17 & $\operatorname{resid} d_{j}$ & 7.98 & 0.00 & 129.97 & 2351.13 \\
\hline 3.rd allocation & 14.74 & $4-3$ & s4 & 54.96 & d3 & 346.56 & resid $s_{i}$ & 129.97 & 216.59 & 0.00 & 3192.56 \\
\hline 4.th allocation & 10.72 & $5-4$ & s5 & 323.14 & $\mathrm{~d} 4$ & 258.12 & resid $d_{j}$ & 216.59 & 0.00 & 106.54 & 1142.16 \\
\hline 6.th allocation & 20.77 & $3-5$ & s3 & 278.46 & d5 & 294.30 & resid $s_{i}$ & 106.54 & 187.76 & 0 & 3899.67 \\
\hline 7.th allocation & 3.35 & $7-6$ & s7 & 186.73 & d6 & 283.58 & resid $d_{j}$ & 187.76 & 1.03 & 0.00 & 3.44 \\
\hline 8.th allocation & 2.01 & $8-7$ & s8 & 362.53 & d7 & 276.21 & $\operatorname{resid} d_{j}$ & 1.03 & 0.00 & 361.51 & 726.63 \\
\hline 9.th allocation & 5.36 & $6-8$ & s6 & 180.16 & $\mathrm{~d} 8$ & 264.15 & resid $s_{i}$ & 361.51 & 0.00 & 97.36 & 521.83 \\
\hline 10.th allocation & 26.80 & $1-9$ & s1 & 310.63 & d9 & 282.91 & resid $s_{i}$ & 97.36 & 185.55 & 0.00 & 4972.83 \\
\hline 11.th allocation & 10.72 & $9-10$ & s9 & 193.71 & $\mathrm{~d} 10$ & 280.90 & resid $d_{j}$ & 185.55 & 0.00 & 8.16 & 87.45 \\
\hline 12.th allocation & 24.79 & $13-12$ & s13 & 383.39 & $\mathrm{~d} 12$ & 673.52 & resid $s_{i}$ & 8.16 & 665.36 & 0.00 & $16,494.32$ \\
\hline 13.th allocation & 45.56 & $13-11$ & s13 & 383.39 & d11 & 0.00 & resid $d_{j}$ & 665.36 & 281.97 & 0 & $12,846.45$ \\
\hline
\end{tabular}

The optimal transport values from the two roads are the following:

Simulation $1=51295$;

Simulation $2=46319$

\section{Procedure for Solving the Transport Problem}

This procedure can be adopted preferably in case some information are available ex ante as graph map, distance, road condition, or preference about the route that could facilitate the search for the optimal transport solution.

The problem is the same, minimization of the transport cost: $c_{i j}$ is the unit cost of transport; the 16 nodes and branches are forming the network that shows possible alternative routes to ship the whey from nodes $i$ (origin) to nodes $j$ (destination), $X_{i j}$ is the quantity of whey shipped from $i$ to $j$. We start by solving the problem previously illustrated in Figure 3 with 5 nodes and 8 branches. The problem is to find the minimum transport cost of the 8 branches subject to the 5 node constraints.

$$
\text { OF : } 6 X_{1,2}+X_{1,3}+4 X_{2,5}-3 X_{3,2}+2 X_{3,4}+4 X_{4,1}+X_{4,2}+3 X_{4,5}
$$

s. t. (maximum flow through the node-archs; the values are selected with the branch capacity) node-arch 1: $X_{1,2}+X_{1,3}-X_{1,4}=(1$ branch with negative versus, max. capacity $=5$ )

Node arch 2: $X_{2,5}-X_{2,1}-X_{2,3}-X_{2,4}=-4$ (2 branches with negative versus, max. capacity $=-4$ )

Node arch 3: $-X_{3.2}+X_{3.4}-X_{3.1}=0$ (1 branch with negative versus, max. capacity $=-4$

Node arch 4: $X_{4.1}+X_{4.2}+X_{4.5-}-X_{4.3}=1$ (1 branch with negative versus, max. capacity $=1$ 
Node arch 5: $-X_{5,2}-X_{5,4}=-3 \quad(2$ branches with negative versus, max. capacity $=-3$ )

Route options: The Figure 3 gives the information to create the incidence matrix node-arch A: for the 5 nodes $\mathrm{v}(1 \ldots 5)$ and arch $e(1 \ldots 8)$ the corresponding entry $A_{v e}$ is:

+1 if $e$ exit from $v$ ( $v$ is the tail of $e=$ positive branch direction);

-1 if $e$ entry in $v((v$ is the head of $e=$ negative branch direction $)$;

0 , otherwise (not allowed flow).

The incidence matrix described in Table 6 reports the constraints: the value 1 means that the transport has the positive versus from the origin node $i$ to the destination nodes $j$; the negative sign indicates the opposite direction required when one of the positive branches is not allowed.

Parameters

$0 \subseteq V$; origin nodes

$D \subseteq V$; destination nodes

$T \subseteq V$; passage nodes

$s_{i}$, for $i \in 0$, supply product vertix $i$

$d_{i}$, for $i \in D$, demand product vertix $i$

$X_{i j}$ for $i, j \in A$ flow of product on the arch $i, j$

$u_{i j}$ for $i, j \in A$, capacity of the arch $i, j$ (maximum admittable flow on the arch)

$c_{i j} * x_{i j},(\mathrm{i}, \mathrm{j}) \in A$ is the transport cost of the flow $X_{i j}$ on the arch $i, j$

The second version of the transport problem is represented in Table 7 in LP notation:

Table 6. Incidence matrix-node-arch designed on the constraint of the LP formulation.

\begin{tabular}{|c|c|c|c|c|c|c|c|c|c|c|c|c|c|c|c|c|}
\hline Node-arch A & $\mathrm{X}_{1,2}$ & $\mathrm{X}_{1,3}$ & $\mathrm{X}_{1,4}$ & $\mathrm{X}_{2,1}$ & $\mathrm{X}_{2,3}$ & $\mathrm{X}_{2,4}$ & $\mathrm{X}_{2,5}$ & $\mathrm{X}_{3,1}$ & $\mathrm{X}_{3,2}$ & $\mathrm{X}_{3,4}$ & $\mathrm{X}_{4,1}$ & $\mathrm{X}_{4,2}$ & $\mathrm{X}_{4,3}$ & $\mathrm{X}_{4,5}$ & $\mathrm{X}_{5,2}$ & $\mathrm{X}_{5,4}$ \\
\hline 1 & 1 & 1 & -1 & & & & & & & & & & & & & \\
\hline 2 & & & & -1 & -1 & -1 & 1 & & & & & & & & & \\
\hline 3 & & & & & & & & -1 & 1 & 1 & & & & & & \\
\hline 4 & & & & & & & & & & & 1 & 1 & -1 & 1 & & \\
\hline 5 & & & & & & & & & & & & & & & -1 & -1 \\
\hline
\end{tabular}

Table 7. Transport problem representation.

\begin{tabular}{|c|c|c|c|c|c|c|}
\hline & & \multicolumn{5}{|c|}{ destination $\mathrm{J}=1 . . \mathrm{n}$} \\
\hline & & 1 & 2 & $j$ & $\mathrm{n}$ & limit \\
\hline & 1 & $c_{1,1} X_{11}$ & $\mathrm{c}_{1,2} \mathrm{X}_{12}$ & $\cdots$ & $\mathrm{c}_{1, \mathrm{n}} \mathrm{X}_{1 \mathrm{n}}$ & $\mathrm{s}_{1}$ \\
\hline & 2 & $c_{21} X_{21}$ & $\mathrm{c}_{2,2} \mathrm{X}_{22}$ & $\cdots$ & $c_{2, n} X_{2 n}$ & $\mathrm{~s}_{2}$ \\
\hline \multirow{4}{*}{$\begin{array}{c}\text { Source }=s_{P} \text {, row } 1 . . \mathrm{m} \\
(\text { whey supply) }\end{array}$} & $i$ & & & & & \\
\hline & . & & & & & \\
\hline & $m$ & $\mathrm{c}_{\mathrm{m}, 1} \mathrm{X}_{\mathrm{m} 1}$ & $\mathrm{c}_{\mathrm{m}, 2} \mathrm{X}_{\mathrm{m} 2}$ & $\cdots$ & $c_{\mathrm{m}, \mathrm{n}} \mathrm{X}_{\mathrm{mn}}$ & $\mathrm{s}_{\mathrm{m}}$ \\
\hline & $\begin{array}{c}\text { Demand } \\
\qquad d_{j}\end{array}$ & $\mathrm{~d}_{1}$ & $\mathrm{~d}_{2}$ & & $d_{n}$ & \\
\hline
\end{tabular}


The values at the right and bottom sides of the transportation Table 7 indicate respectively: The row reports for a given source of whey $s_{i}$ for $i=1, \cdots, 16$ the number of possible destination (allocation) $j$ for $j=1, \cdots, n$; for $n=16$

A column indicates the whey supply from the sources $s_{i}$ for $i=1, \cdots, 16$ to the $m$ demand $d_{j}$ for $j=1, \cdots, m$ that are the quantity supplied to each demand. In Table 8 is reported the numeric solution of the problem.

$C_{i j}$ for $1 \leq i \leq m$ and $1 \leq j \leq n$ is the unit cost of shipping the whey from the $i$-th source to the $j$-th destination;

$X_{i j}$ is the quantity of whey shipped from $i$-th source to $j$-th destination;

$C_{i j} * X_{i j}$ is the total transport cost from source (node $i$ ) to destination (node $j$ ) for all $i, j$. pair combinations (from the first to the last allocation).The cost cells are distributed in continuous:

$$
\text { OF : } C_{1,1} X_{1,1}=464 X_{11} ; C_{1,2} X_{1,2}=513 X_{1,2} ; C_{3,4}=685 X_{3,4}
$$

For the equilibrium condition it is required:

$\sum_{i=1}^{m} S_{i}=\sum_{i=1}^{n} d_{i}$ then (see Table 8):

$750+1250+1000=800+650+700+850=3000$ i.e. demand = supply then this problem is balanced.

\subsection{Use of the Procedure 2 for the Case Study}

This procedure is used to solve the problem of the minimum transport cost from the CP origins to WPP destination with cost simulations of some predefined routes to fulfill specific objectives of the operators. The Table 5 previously described is adapted to this problem by using the incidence matrix to define the preferred routes. The optimal value is obtained from the following operation:

MATR. SOMMA. PRODUCT (B98:S115; B123:S140)

The first matrix B98:S115 reports the whey quantity multiplied by the adjusted distances (see Table 5), and transport cost from origin to destination; the 2nd matrix (B123:S140) reports the numeric coefficients of the incidence matrix: to generate the routes and calculate the corresponding costs.

\section{Objective Function and Coefficients}

The route is specified with coefficient value $=1$ for positive direction and -1 for the opposite direction of the branch while the non activated branch is indicated with nul value 0 . The objective function minimizes the transport cost between a given CP (origin) and the WPP (destination); the total cost will be calculated by

Table 8. Unit transport cost $c_{i, j^{*}}$

\begin{tabular}{ccccccc}
\hline & & \multicolumn{4}{c}{ Destination (demand) $=$ row } & Supply \\
\hline & Source & 1 & 2 & 3 & 4 & limit \\
\hline Source = row & 1 & $\mathrm{c}_{1,1}=464$ & $\mathrm{c}_{1,2}=513$ & 654 & 867 & 750 \\
\multirow{2}{*}{ (supply) } & 2 & 352 & 416 & 690 & 791 & 1250 \\
& 3 & 995 & 682 & 388 & $c_{3,4}=685$ & 1000 \\
\multirow{2}{*}{ demand } & Allocation & 800 & 650 & 700 & 850 & \\
\hline
\end{tabular}


summing the costs of various branches composing the route: $C T=\sum\left(C_{i j} * X_{i j}\right)$ (see Figure 3.1). Each node can only have one path to it and one path from it. The horizontal constraints are the supply (from) constraint and the vertical constraints are the demand (to) constraints. Forcing the sum of the "from" origin constraints to be equal to 1 will force the solver to choose only one path from each node. Forcing the sum of the "to" destination constraints to be equal to 1 will force the solver to choose only one path for a given node. The first group of simulations is computed by shipping the whey from the all CP to Trento destination that is also the main whey producer and where it is located the WPP location (Table 9).

Table 10 reports the incidence matrix with transportation cost and delivery to Trento following the routes designed by the operator. The first route is the circuit encompassing ten $\mathrm{CP}$ of the first quadrant in Figure 4 with starts to CP: Mezzana, Terzuolas, Rumo, Revo, Castelfondo, Fondo, Cavareno, Rumeno, Coredo Tuenno with end to Trento; the second route is composed by three CP: Cavalese, Predazzo and Val di Fassa and end to Trento; the third route is the circuit Fiera di Primiero and Lavarone and end to Trento. Assuming the whey delivery to Trento, the OF value is $62,211 €$. Other three simulations are tried by shifting the final destination (F.D). The results are: F.D-Tuenno: $\mathrm{OF}=$ 58,257; F.D-Coredo: $\mathrm{OF}=76,706$; F.D-Cavalese: $\mathrm{OF}=213,961$. The results suggest these considerations: the optimal solution is found in the area where the higher supply of whey is compatible with minimum transport cost; Tuenno is the optimal location for whey delivery in absence of WPP contraints. The plants are presently located in Trento because is the highest whey supplier and the whey collection is easier. The 2nd procedure is quite interesting as it reveals the optimal position of WPP in Tuenno. Compared to Trento, the WPP located in Tuenno reduces the present transport cost of 6.3\%; the WPP located in Coreno increases the transport cost of $23 \%$ and location in Cavalese increases the cost of $244 \%$.

Compared the second with the first procedure, the transport cost with destination Trento are quite similar, the difference is $15.5 \%$ and is explained by the differences in route 2 and 3 followed to ship the product to Trento. Sustainability of the collection strategy is an important collateral effect of the transport: the available technologies to process the whey contribute to limit the dispersion of whey pollutants in the environment and demonstrate that economic and environmental targets of the whey processing can be simultaneously obtained. The production, processing and transportation of milk products, contributes with 2.7 percent to the global anthropogenic greenhouse gas emissions in Italy. According to the methodology of the IPCC [4], the total annual $\mathrm{CO}_{2}$ emissions from the transport sector calculated as follows:

The whey transport emission is computed by assuming that $\mathrm{CO}_{2}$ emission of a normal diesel truck with capacity of 20 ton and emission of $20 \mathrm{~g} \mathrm{CO}_{2}$ eq per ton/ $\mathrm{km}$. This coefficient has been used to compute the whey pollution due transport. The $\mathrm{CO}_{2}$ emissions are: route $1=15.20$; route $2=12.05$; route $3=245.29$; total 


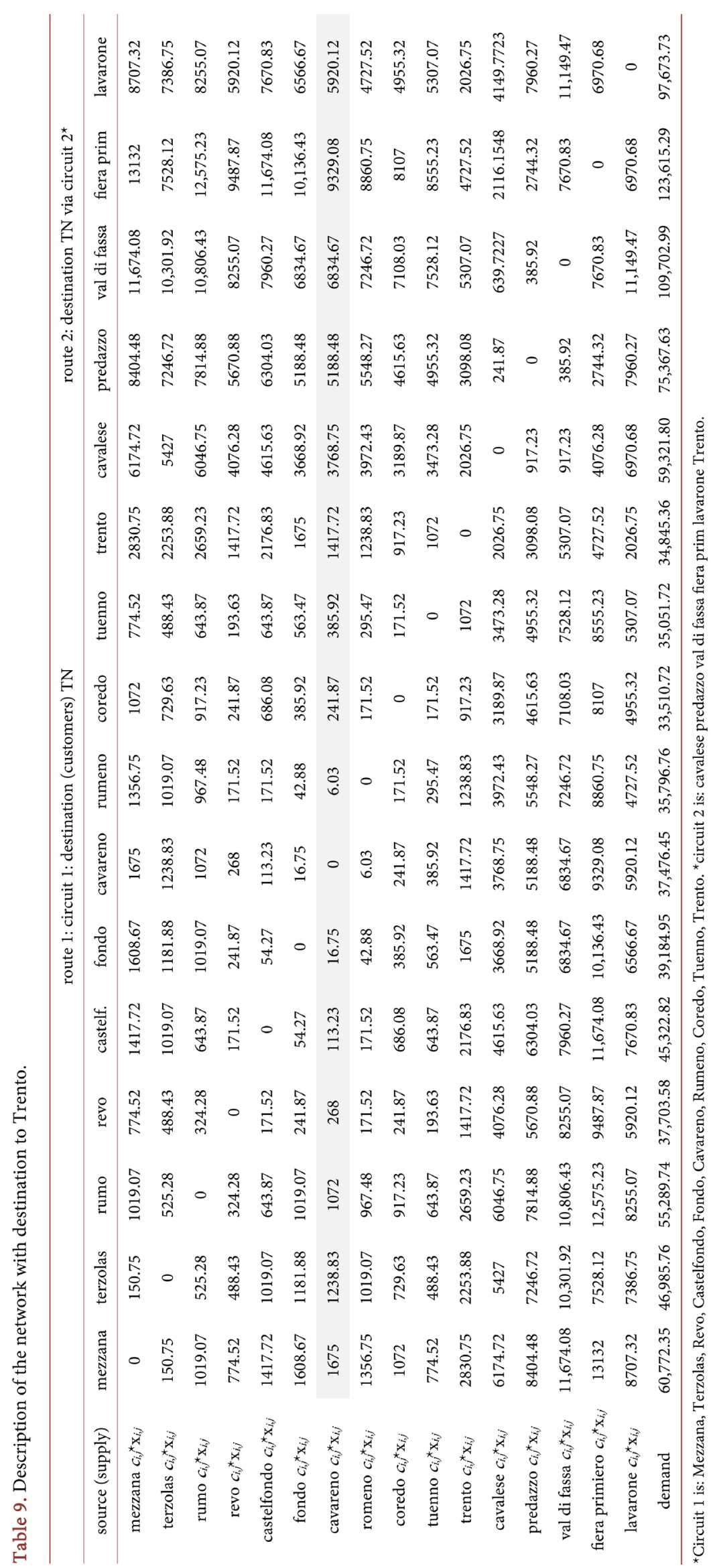


Table 10. Incidence matrix to compute the minimum cost from previous network.

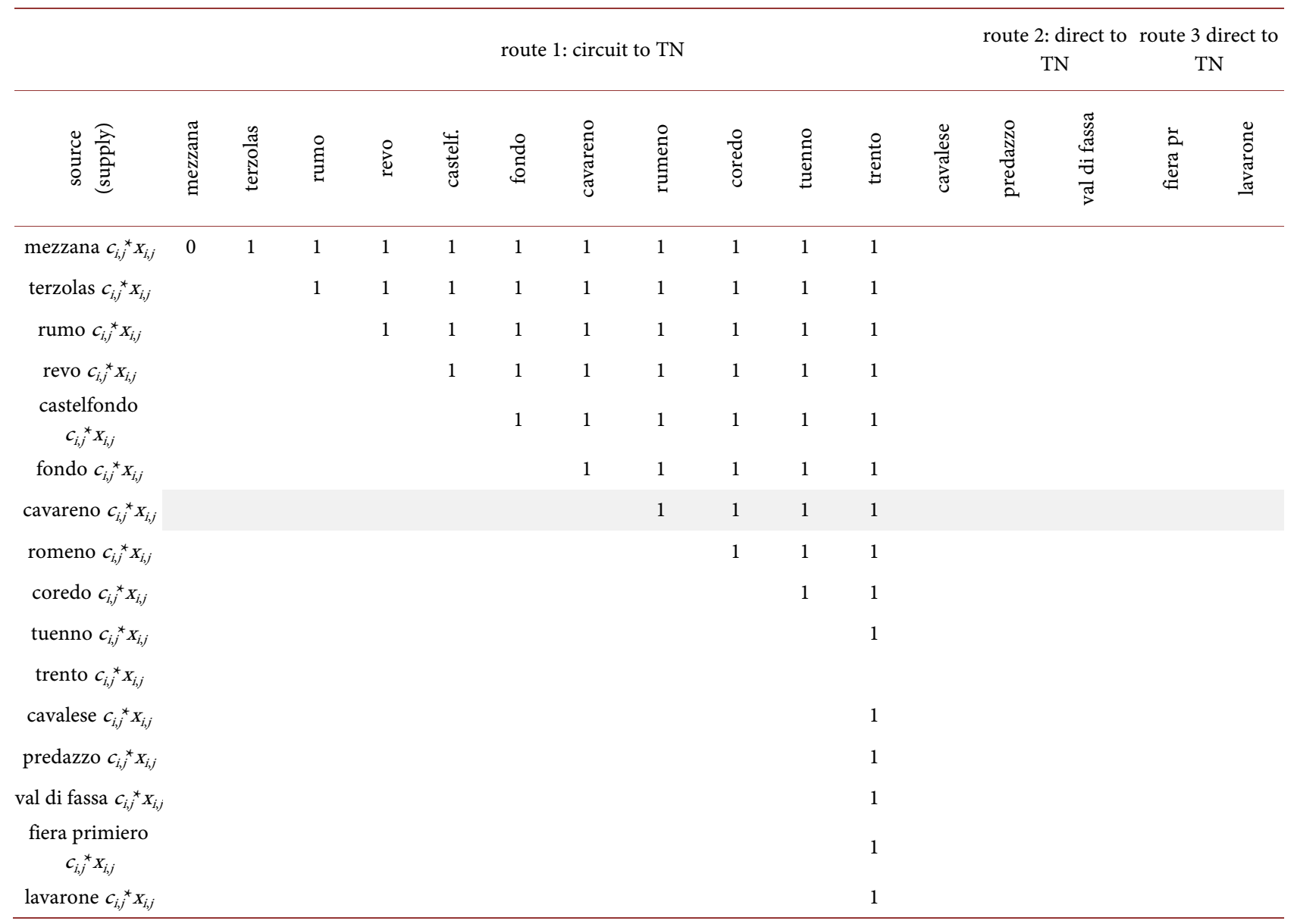

$\mathrm{CO}_{2}$ emission $=272.54$. Compared with the BOD and COD of the whey released in water this emission procure a minor pollution impact and justify the exploitation of whey recycling strategy.

\section{Policy Target}

Turning the waste into a resource is the main target of the circular economy. The objectives and targets set in European legislation have been key drivers to improve the waste management, to stimulate innovation in recycling, to limit the use of landfilling, and create incentives to change consumer behavior. The re-manufacture, reuse and recycle, of the waste of dairy industry is a valuable contribution to the circular economy. Then the following policy targets could be achieved with whey recycling:

1) Diversion of waste from the landfill

Based on the waste hierarchy, a key objective of the government policy is to reduce the level of the whey dispersion and profitable use of the cheese industry by-products. Environmental Regulations and Landfill Allowance Scheme are a policy solution to limit waste dispersion;

2) Increased recycling

The government's objective is to make easier for dairy chain to incentive the 
diffusion of whey recycling methods. Several measures have been put in action to make the waste a resource by exploiting new technologies as the bacteria fermentation and micro-ultra-filtration methods. One suggestion is to introduce compulsory use of bio-plastic bags handed out by large retailers. These policies aim to encourage customers to reuse their shopping bags, and reduce waste and littering.

3) Waste reduction from the economy

The amount of waste produced by cheese plants and dairy industries is relevant... For instance, the Producer Responsibility Obligations (Packaging Waste) place responsibility on the producers of packaging waste to recover and recycle a certain amount of packaging. They are also required to design their products in such a way that encourages easy dismantling and recycling at the end of the bioplastic life cycle.

4) Invest into research and innovation

There are now available a number of whey processing technologies (mechanical, chemical, microbiological) to decompose the whey in its elementary component to be sold in the market to increase the original whey value added. A promising whey processing is to use the lactose to produce bio-polymers that are programmed to decompose and mineralize in shorter time. But these biotechnologies are not yet competitive compared to the traditional plastic production.

\section{Conclusion}

This research is a contribution to solve the logistic problem to minimize the transport cost and reduce the pollution caused by the whey transport and find the optimal location of the whey processing plant. This search included 16 cheese processing plants (CP) located in Trentino A. A. region, integrated in the whey network oriented to Trento and the scope was to minimize the distance from all CP to WPP to reduce costs and environmental impact caused by the $\mathrm{CO}_{2}$ emission. The problem required to design the road map; the road information was collected from Google Map to design accurately the CP network, the preferred routes and corrected distances from origin to destination to take according of the nature of territory. Two procedures were adopted, the first one was the emulation of the simplex method and was developed with two simulations, one referred to the general network the other by imposing route limitations determined by the preferences of the operators. The second procedure was based on the same network description but used the incidence matrix to define routes requiring some preliminary knowledge of the territory and road network according with the operators' needs. Different route simulation were tested and the results suggested Tuenno the optimal location of WPP in absence of constraints due to the supplementary costs required to move the plants from Trento to Tuenno. The two procedures showed similar results, but the first one is methodologically recommended while the second one appears to be empirical and need to need to make some assumptions about road options for the calculus. 


\section{References}

[1] AAVV (2008) Economic Impact of the Abolition of the Milk Quota Regime: Regional Analysis of the Milk Production in the EU. A report prepared by IPTS with the collaboration of EuroCARE GmbH, Bonn.

[2] Mattew, A. (2008) Milk Quota Removal Could Cost EU Farmers €4 Billion, Cap reform. EU.

[3] Weaver, R.D., Rosa, F. and Vasciaveo, M. (2016) Check the Dairy Chain Efficiency in Italy. $R E A, 71,60-76$.

[4] IPCC (1996) Revised Guidelines for National Greenhouse Gas Inventories, Vol. 2.

[5] Wissmann, M.A., Follmann, H.J. and Rachow, N. (2012) Environmental Costs: Analysis of Its Impact and Importance in the Pursuit of Eco-Efficiency in an Industry of Cheese. Custos e Agronegocio, 8, 2-23.

[6] Durham, R., Sleigh, R. and Hourigan, J. (2004) Pharmaceutical Lactose: A New Whey with No Waste. Australian Journal of Dairy Technology, 59, 138-141.

[7] Jelen, P. (2009) Dried Whey, Whey Proteins, Lactose and Lactose Derivative Products. In: Tamime, A.Y., Ed., Dairy Powders and Concentrated Products, Wiley- Blackwell, Oxford, UK, 255-267.

[8] Klerkx, L. and Nettle, R. (2013) Achievements and Challenges of Innovation Co- Production Support Initiatives in the Australian and Dutch Dairy Sectors: A Comparative Study. Food Policy, 40, 74-89.

[9] Gellinck, X. and Kuhne, B. (2008) Innovation in Traditional Food Network. Proceeding of the 2 nd International European Forum on System Innovation in Food Network.

[10] Rosa, F. (2012) Planning the Sustainable Agri-Fuel Supply Chain. Paper presented to the 1st AIEAA Conference-Toward a Sustainable Bio-Economy: Economic Issues and Policy Challenges, 4-5 June 2012.

http://ageconsearch.umn.edu/bitstream/124130/2/Rosa_Planning\%2520the\%2520Sustai nable\%

[11] Pinto, G. and Giordano, R. (2009) Bioprocess Systems Engineering Applied to the Production of Protein Hydrolysates in a Multipurpose Plant. Computer Aided Chemical Engineering, 27, 1887-1892.

[12] Melkote, S. and Daskin, M. (2001) Capacitated Facility Location/Network Design Problems. European Journal of Operational Research, 129, 481-495.

[13] Melkote, S. and Daskin, M. (2001) An Integrated Model of Facility Location and Transportation Network Design. Transportation Research Part A: Policy and Practice, 35, 515-538.

[14] Mesbahuddin Ahmed, M., Khan, A.R., Ahmed, F. and Uddin, S. (2016) Incessant Allocation Method for Solving Transportation Problems. American Journal of Operations Research, 6, 236-244. https://doi.org/10.4236/ajor.2016.63024

[15] Ahuja, R.K., Magnanti, T.L. and Orlin, J.B. (1993) Network Flows: Theory, Algorithms, and Applications. Prentice Hall, Upper Saddle River

[16] Doganis, P. and Sarimveis, H. (2008) Optimal Production Scheduling for the Dairy Industry. Annals of Operations Research, 759, 315-331. https://doi.org/10.1007/s10479-007-0285-y

[17] Hillier F.S. and Lieberman, G.J. (1974) Operation Research. Holden Day, Inc., San Francisco.

[18] Lazzarini, S.G., Chaddad, F.R. and Cook, M.L. (2001) Integrating Supply Chain and Network Analyses: The Study of Netchains. Chain and Network Science, 1, 7-22. https://doi.org/10.3920/JCNS2001.x002 


\section{Appendix 1}

The methodology COPERT estimates $\mathrm{CO}_{2}$ emissions based on the fuel consumption, assuming that the carbon content in it is brought around at the state of maximum oxidation, or $\mathrm{CO}_{2}$.

In case you want to calculate the total emissions of carbon dioxide is used to calculate stoichiometric, assuming that all carbon is oxidised to carbon dioxide, with the following formula:

$$
E_{\mathrm{CO}_{2}}^{\mathrm{CALC}}=44.01 \times \frac{F C}{12.01+1.01 r_{H C}}
$$

where, $r_{H-C}$ is the ratio of number of hydrogen and carbon atoms in the fuel used( $\sim 1.8$ to $\sim 2.0$ for petrol and diesel).

$F C$ is the fuel consumption, in weight

$E_{\mathrm{CO}_{2}}^{\mathrm{CALC}}$ is the $\mathrm{CO}_{2}$ emissions calculated by weight with the same units as above

In case it is intended to calculate the carbon dioxide emissions at the exhaust tube of the vehicles it should be considered the quantities of carbon contained in the emissions carbon monoxide, volatile organic compounds and particulate matter. It applies to the following formula:

$$
E_{\mathrm{CO}_{2}}^{\mathrm{CALC}}=44.01 \times \frac{F C^{\mathrm{CALC}}}{12.01+1.01 r_{H: C}}-\frac{E^{C O}}{28.01}-\frac{E^{\mathrm{VOC}}}{13.85}-\frac{E^{P M}}{12.01}
$$

where

$$
\begin{aligned}
& E^{C O}=C O \text { emissions by weight per mole of fuel combusted } \\
& E^{\mathrm{VOC}}=\mathrm{VOC} \text { emissions by weight per mole of fuel combusted } \\
& E^{P M}=\text { carbon emissions for moli of combusted fuel }
\end{aligned}
$$

From the foregoing it is the implicit assumption that the hydrocarbon mixture is the result solely from hydrogen and carbon components. In fact in the Formulation (2), relatively to the part for calculating the stoichiometric amount of carbon dioxide produced, are considered only the atomic weights of carbon and hydrogen. 
Submit or recommend next manuscript to SCIRP and we will provide best service for you:

Accepting pre-submission inquiries through Email, Facebook, LinkedIn, Twitter, etc. A wide selection of journals (inclusive of 9 subjects, more than 200 journals)

Providing 24-hour high-quality service

User-friendly online submission system

Fair and swift peer-review system

Efficient typesetting and proofreading procedure

Display of the result of downloads and visits, as well as the number of cited articles Maximum dissemination of your research work

Submit your manuscript at: http://papersubmission.scirp.org/

Or contact ajor@scirp.org 